\title{
Sistem monitoring kemiringan gedung berbasis resistor variabel
}

\author{
Reza Pahlevi, Hartono*, dan Farzand Abdullatif \\ Jurusan Fisika Fakultas Matematika dan Ilmu Pengetahuan Alam \\ Universitas Jenderal Soedirman Purwokerto \\ Jl. Dr. Soeparno 61, Kampus Unsoed Karangwangkal \\ *email: harlaras@gmail.com
}

\begin{abstract}
Abstrak - Sistem deteksi kemiringan gedung bertingkat dibuat menggunakan resistor variabel yang dipasang bandul sebagai sensor. Bandul selalu menghadap ke bawah karena adanya gaya gravitasi. Gaya gravitasi berfungsi sebagai torsi untuk merubah resistansi resistor variabel. Resistor variabel disusun menjadi rangkaian pembagi tegangan supaya perubahan resistansinya berubah menjadi perubahan beda potensial yang dapat dibaca oleh arduino. Peningkatan sensitivitas dilakukan dengan memasang resistor variabel pada sebuah gear kecil dan bandul pada gear besar. Kedua gear dihubungkan secara bersinggungan. Sensor dibuat sebanyak 2 buah untuk mendeteksi perubahan kemiringan terhadap sumbu x dan sumbu y. Hasil yang didapatkan yaitu sistem deteksi kemiringan gedung bertingkat dapat dibuat menggunakan resistor variabel. Sistem deteksi memiliki karakteristik yang baik dengan akurasi sebesar $89,34 \%$, presisi $91,07 \%$, eror $10,66 \%$, dan waktu respon 4,125 detik. Sistem deteksi kemiringan dapat mendeteksi perubahan kemiringan sudut dan arahnya serta dapat memberikan peringatan dini setelah sudut yang terbaca melebihi $1,5^{\circ}$. Threshold yang dimiliki sistem adalah $0,17^{\circ}$.
\end{abstract}

Kata kunci: resistor vaariabel, torsi, sensitivitas, karakteristik.

Abstract - The tilt detection system of multi-storey buildings are made using a variable resistor mounted by the pendulum as a sensor. The pendulum always faces down because of the force of gravity. The force of gravity serves as the torque to change the resistance of the variable resistor. Variable resistors are arranged into a voltage divider circuit so that the transform in resistance turned into alteration in difference of potential, which can be read by Arduino. The increasing of sensitivity, a variable resistor is mounted on a small gear and a large gear pendulum. Then the two gears get contact. Two sensors are made to detect the alteration in the slope of the $x$ axis and $y$ axis. The result is the slope detection system of multi-storey buildings can be made using a variable resistor. The detection system has good characteristics with an acceleration of $89.34 \%$, a precision of $91.07 \%$ error of $10.66 \%$, and a response time of 4.13 seconds. The tilt detection system can detect changes in tilt angel and direction and can provide an early warning after the angel reading exceeds $1,5^{\circ}$. The system threshold is $0.17^{\circ}$.

Key words: variable resistor, torque, sensitivity, caracteristics

\section{PENDAHULUAN}

Kemiringan pada konstruksi suatu bidang atau benda menjadi salah satu parameter dalam menentukan kekuatan konstruksi. Kemiringan suatu gedung dapat menjadi hal fatal apabila tidak diantisipasi secara dini. Ada banyak alat ukur kemiringan yang pernah dibuat, salah satunya yaitu dengan menggunakan sensor akselerometer ADXL335 [1] dan Giroskop yang digunakan untuk pengukuran sudut momen roket [2]. Alternatif lain dalam mendeteksi kemiringan gedung bertingkat dapat dibuat menggunakan resistor variabel.

Resistor variabel ialah resistor yang resistansinya dapat diubah-ubah. Resistor variabel mempunyai tiga sambungan, dua buah untuk ujungnya dan sebuah untuk pejalan [3].
Keluaran resistor variabel ini berupa resistansi yang linier sehingga dapat digunakan untuk mengukur perubahan sudut dari perubahan resistansi [4]. Resistor variabel memiliki berbagai macam jenis, salah satunya adalah jenis putar. Nilai resistansinya dapat diubah apabila porosnya diputar.

Resistor variabel dapat diputar dengan momen gaya atau torsi yang lebih besar dari momen inersia yang dimiliki oleh resistor variabel. Torsi merupakan besaran yang memiliki peran sama dengan gaya $(F)$ pada gerak linier, namun memeliki prinsip yang berbeda. Torsi adalah besarnya gaya yang dipengaruhi oleh jarak gaya terhadap pusat rotasi (lengan gaya r) seperti Gambar 1. Ketika sebuah benda diam diberi torsi, maka terdapat 
besaran yang mempertahankan untuk berotasi atau melawan rotasi yang dinamakan momen inersia (momen kelembaman). Semakin besar nilai momen inersia suatu benda, maka semakin sukar benda untuk diputar [5]. Persamaan torsi $(\tau)$ seperti persamaan berikut ini.

$$
\tau=F r
$$

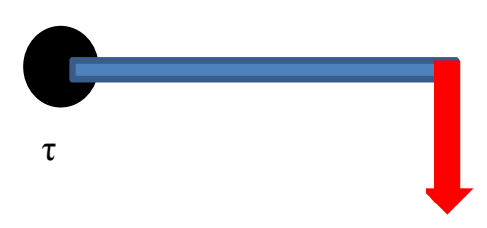

Gambar 1. Momen gaya atau torsi

Gaya dihasilkan oleh gaya berat bandul. Bandul dipasang pada gear yang lebih besar sedangkan resistor variabel dipasang pada gear kecil. Kemudian kedua gear tersebut disinggungkan seperti Gambar 2. Hubungan dua gear yang saling bersinggungan memiliki arah putar berlawanan antar gear dan memiliki kelajuan linear yang sama atau dapat ditulis dalam persamaan:

$$
v_{1}=v_{2} \text { atau } \omega_{1} r_{1}=\omega_{2} r_{2}
$$

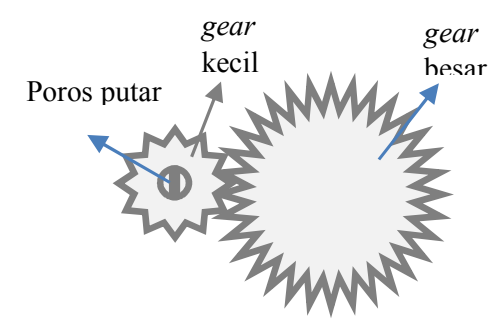

Gambar 2. Hubungan antar gear

Sedangkan hubungan yang dimiliki oleh gear kecil dengan poros putar resistor variabel merupakan hubungan dua gear yang seporos. Hubungan antar gear ini memiliki arah putar dan kecepatan sudut yang sama atau dapat ditulis dalam persamaan:

$$
\omega_{1}=\omega_{2}
$$

Berdasarkan Persamaan (2) dan Persamaan (3), jika terjadi perputaran yang kecil pada gear besar maka akan menghasilkan putaran yang besar pada gear kecil dan poros putar resistor variabel.

Resistor variabel yang digunakan disusun menjadi rangkaian pembagi tegangan seperti Gambar 3, dengan $\mathrm{R}_{2}$ adalah hambatan sensor (resistor variabel). Ketika resistansi pada $\mathrm{R}_{2}$ berubah maka akan terjadi perubahan tegangan keluaran pada rangkaian [6]. Besarnya tegangan keluaran yang dihasilkan oleh rangkaian pembagi tegangan adalah:

$$
V_{\text {out }}=\frac{R_{2}}{\left(R_{2}+R_{1}\right)} V_{\text {in }}
$$

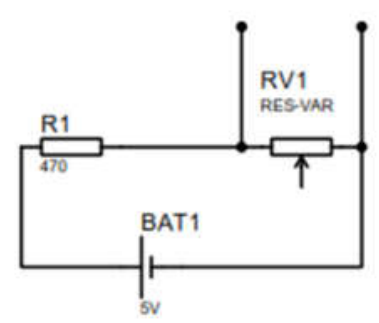

Gambar 3. Rangkaian pembagi tegangan

\section{METODE PENELITIAN/EKSPERIMEN}

Sensor dapat mendeteksi kemiringan apabila resistor variabel dipasang sebuah bandul. Bandul akan mempertahankan posisinya menghadap ke bawah akibat dari adanya gravitasi saat gedung mengalami perubahan kemiringan. Ketika terjadi perubahan kemiringan, bandul bekerja sebagai torsi yang mengubah besarnya resistansi resistor variabel. Gear box dengan rasio 1:3 digunakan untuk meningkatkan sensitivitasnya, seperti ditunjukkan pada Gambar 4.

Sensor dirangkai menjadi rangkaian pembagi tegangan yang terdiri dari resistor tetap $470 \Omega$ dan resistor variabel $1 \mathrm{k} \Omega$ seperti Gambar 3. Nilai $1 \mathrm{k} \Omega$ dipilih agar ketika terjadi perputaran kecil pada resistor variabel maka akan menghasilkan perubahan resistansi yang kecil juga. Keluaran sensor dihubungkan dengan arduino UNO sebagai mikrokontrol untuk diproses dan ditampilkan kemiringan yang dideteksi sistem melalui LCD. Jika kemiringan yang dideteksi melebihi ambang batas kemiringan gedung, maka buzzer akan aktif sebagai tanda bahaya. Serangkaian sistem dapat ditunjukkan dalam bentuk diagram blok seperti pada Gambar 5. 


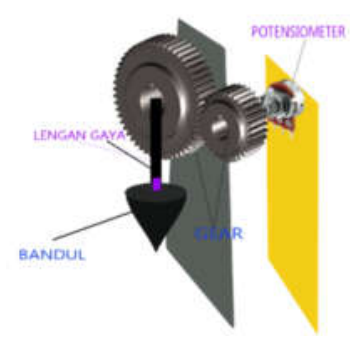

Gambar 4. Rancangan sensor kemiringan gedung.

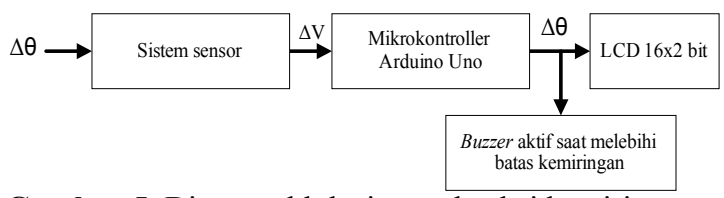

Gambar 5. Diagram blok sistem deteksi kemiringan.

Pengujian sensor dilakukan untuk mengetahui tegangan keluaran minimum dan maksimum yang dapat dihasilkan oleh resistor variabel. Pengujian sensor diawali dengan merangkai resistor variabel dan resistor tetap menjadi rangkaian pembagi tegangan. Tegangan masukan yang diberikan berasal dari power supply sebesar 5 volt. Pada resistor variabel yang dijadikan sebagai sensor dipasang sebuah busur. Busur berfungsi untuk pengujian perubahan tegangan keluaran yang dihasilkan apabila sudut pada resistor variabel divariasikan. Sudut yang divariasikan mulai dari $-90^{\circ}$ sampai $90^{\circ}$ dengan interval $5^{\circ}$.

Resistor variabel dipasang gear box untuk meningkatkan responnya. Setelah digabungkan dengan gear box, sensor diuji kembali responnya terhadap perubahan sudut. Pengujian sensor setelah dipasang gear box dilakukan dengan memvariasikan sudut secara maksimal dari $-59^{\circ}$ sampai $60^{\circ}$. Dari data pengujian tersebut, maka diambil hanya pada bagian respon terbaik.

Pengujian dilanjutkan terhadap sistem sensor dengan menghitung massa bandul minimum yang dibutuhkan untuk dijadikan torsi. Kemudian bandul dengan massa yang cukup disatukan dengan sensor yang sudah terpasang gear box. Setelah itu, sistem sensor diuji respon keluarannya terhadap perubahan sudut dari sudut $0^{\circ}$ sampai $3^{\circ}$ dan $0^{\circ}$ sampai $-3^{\circ}$. Pengujian dilakukan menggunakan papan yang dapasang engsel dan busur, sehingga sistem yang berada diatasnya mengalami perubahan sudut yang sama dengan dan papan dan sesuai yang ditunjukan busur. Jika akurasi yang didapatkan kurang bagus, maka harus dilakukan modifikasi fungsi kalibrasi. Batas sudut pengujian $3^{\circ}$ dipilih karena batas maksimal kemiringan yang diijinkan untuk gedung setinggi $100 \mathrm{~m}$ sebesar $1,6^{\circ}$. Batas ini dihitung berdasarkan pada batas simpangan antar lantai yang diizinkan. Dengan demikian $3^{\circ}$ sudah cukup untuk dijadikan batas pengujian sistem. Sistem sensor dibuat sebanyak 2 buah. Sensor 1 digunakan untuk mendeteksi perubahan kemiringan terhadap sumbu $\mathrm{x}$ dan sensor 2 digunakan untuk mendeteksi perubahan kemiringan terhadap sumbu y.

Pengujian akhir sistem dilakukan diatas papan berbusur dengan memvariasikan sudut dari sudut $0^{\circ}$ sampai $3^{\circ}$. Sudut yang divariasikan meliputi 8 arah mata angin yang disimbolkan dengan $\mathrm{C}, \mathrm{D}, \mathrm{E}, \mathrm{F}, \mathrm{G}, \mathrm{H}, \mathrm{A}, \mathrm{B}$. Hasil pembacaan sistem deteksi dicatat dan dibandingkan dengan sudut yang divariasikan. Perbandingan dilakukan dengan tujuan untuk mengetahui karakteristik sistem deteksi kemiringan gedung. Karakteristik yang diuji meliputi akurasi, presisi, eror, dan waktu respon. Sistem peringatan dini dikatakan dapat bekerja dengan baik apabila sistem deteksi arah kemiringan dengan benar dan buzzer akan aktif setelah melebihi batas kemiringan yang diizinkan. Sistem diatur agar buzzer aktif pada sudut $1,5^{\circ}$, yaitu sudut yang lebih kecil dari $1,6^{\circ}$. Serangkaian pengujian sistem deteksi kemiringan ini dilakukan hanya sebatas skala laboratorium.

\section{HASIL DAN PEMBAHASAN}

Pengujian sensor diawali dengan memposisikan jarum resistor variabel (sensor) pada kondisi $-90^{\circ}$ di atas busur derajat. Variasi sudut dilakukan dengan memutar jarum secara manual hingga mencapai sudut $90^{\circ}$ dengan interval $5^{\circ}$. Hasil dari pengujian respon sensor terhadap perubahan variasi sudut ditunjukkan pada Gambar 6.

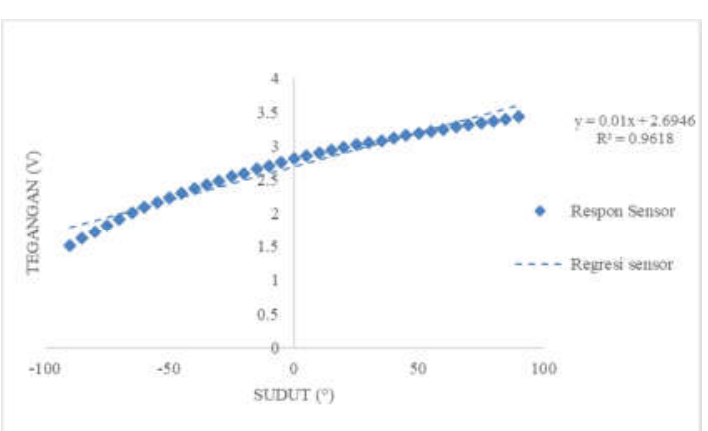

Gambar 6. Respon sensor terhadap perubahan sudut 
Gambar 6 menunjukkan respon keluaran sensor saat diberikan perubahan sudut dari $-90^{\circ}$ sampai $90^{\circ}$. Sensor memiliki sensitivitas sebesar $0,01 \mathrm{~V} /{ }^{\circ}$. Korelasi antara data yang didapatkan dengan fungsi linearnya adalah sebesar 0,96. Nilai sensitivitas sensor dapat ditingkatkan dengan menambahkan gear box. Gear box yang digunakan dalam penilitian ini memiliki rasio $1: 3$, sehingga perubahan $1^{\circ}$ pada sudut sama dengan perubahan $3^{\circ}$ pada sensor.

Hasil pengujian setelah sensor dihubungkan dengan gear box dilakukan pada interval sudut $-59^{\circ}$ sampai $60^{\circ}$. Tegangan masukan digunakan sebesar 5 volt sehingga perubahan maksimum keluaran yang dihasilkan adalah 3,45 volt. Hasil pengujian sensor setelah dipasang gear box ditunjukkan pada Gambar 7 .

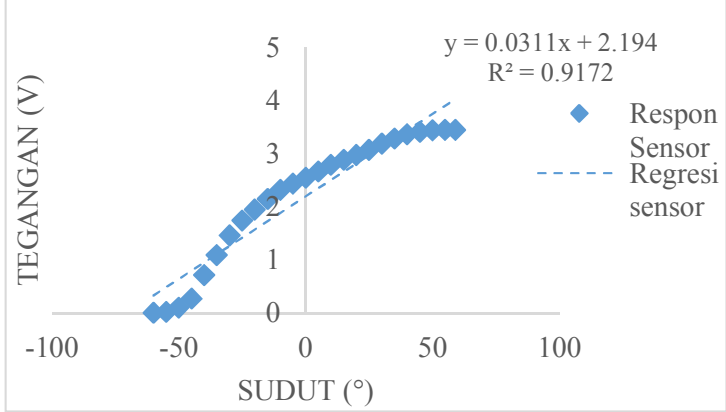

Gambar 7. Respon sensor dengan gear bok.

Gambar 7 menunjukkan bahwa resistor variabel bersifat tidak linear. Korelasi data yang didapatkan dengan fungsi linear anatara sensor sebelum dipasangkan gear bok dan setelah dipasang gear bok mengalami penurunan dari 0,96 menjadi 0,91 . Hal ini menggambarkan sensor memiliki pembacaan yang kurang baik. Akan tetapi sensitivitas sensor meningkat dari $0,01 \mathrm{~V} /{ }^{\circ}$ menjadi $0,03 \mathrm{~V} /{ }^{\circ}$. Dengan batas kemiringan gedung adalah $1,5^{\circ}$, maka agar sensor dapat digunakan dapat diambil pada respon sensor yang memiliki korelasi paling bagus yaitu rentang sudut $-10^{\circ}$ sampai sudut $30^{\circ}$ seperti ditunjukkan pada Gambar 8 .

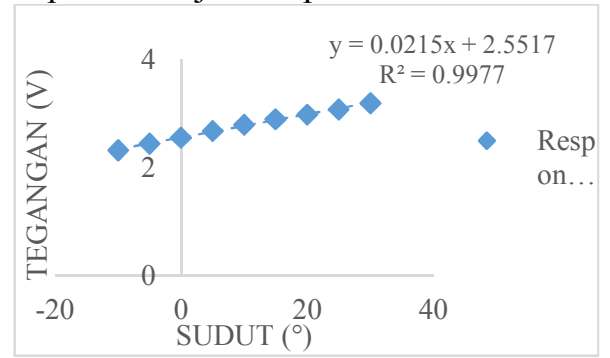

Gambar 8. Respon sensor dari sudut $-10^{\circ}$ sampai $30^{\circ}$
Gambar 8 merupakan respon sensor setelah dipasang gear bok saat terjadi perubahan sudut $-10^{\circ}$ sampai $30^{\circ}$. Sensor memiliki sensitivitas $0,02 \mathrm{~V} /{ }^{\circ}$ dengan korelasi 0,99 dan menghasilkan tegangan keluaran dari 2,32 volt sampai 3,07 volt. Respon ini sudah cukup untuk dijadikan sensor pendeteksi perubahan sudut.

Sensor sudut yang sudah bagus dipasangkan bandul agar menjadi sistem sensor yang dapat mendeteksi perubahan kemiringan. Bandul yang digunakan memiliki massa $0,8 \mathrm{~kg}$. Sistem diuji respon tegangan keluarannya terhadap perubahan sudut bidang dari sudut $0^{\circ}$ sampai sudut $3^{\circ}$ dan sudut $0^{\circ}$ sampai $-3^{\circ}$. Tegangan masukan yang digunakan sebesar 5 volt. Hasil pengujian respon sistem sensor terhadap perubahan sudut ditunjukkan pada Gambar 9.

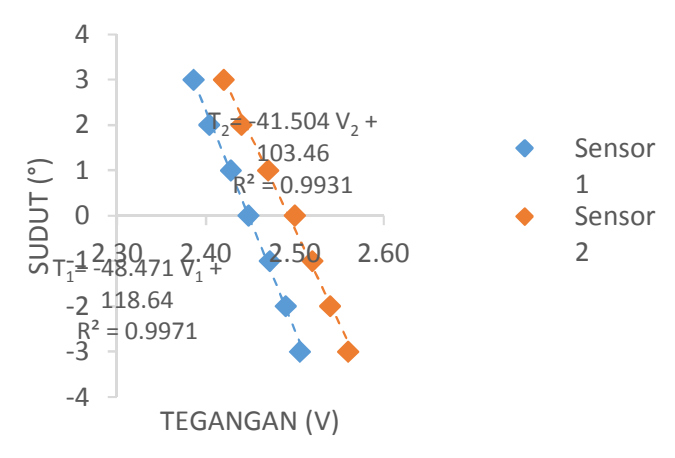

Gambar 9. Fungsi kalibrasi sensor kemiringan

Gambar 9 merupakan fungsi kalibrasi yang dimiliki oleh masing-masing sensor. Dari fungsi kalibrasi tersebut dapat diketahui setiap sensor memiliki sensitivitas sebesar $-48,47 \mathrm{mV} /{ }^{\circ}$ dengan korelasi 0,99 untuk sensor 1 dan $-41,50$ $\mathrm{mV} /{ }^{\circ}$ dengan korelasi 0,99 untuk sensor 2 . Dimana $\mathrm{T}$ merupakan sudut dan $\mathrm{V}$ merupakan tegangan yang dihasilkan. Dengan demikian sensor memiliki respon yang baik untuk mendeteksi perubahan kemiringan. Sehingga fungsi kalibrasi untuk sensor 1 yaitu $\mathrm{T} 1=$ $(-48,471 \mathrm{~V} 1+118,64)$ dan fungsi kalibrasi untuk sensor 2 yaitu $\mathrm{T} 2=(-41,504 \mathrm{~V} 2+$ 103,46). Fungsi kalibrasi ini merupakan fungsi yang dijadikan program untuk arduino. Setelah di program sistem diuji akurasinya. Hasil pengujian sistem sensor setelah di program adalah seperti Gambar 11. 


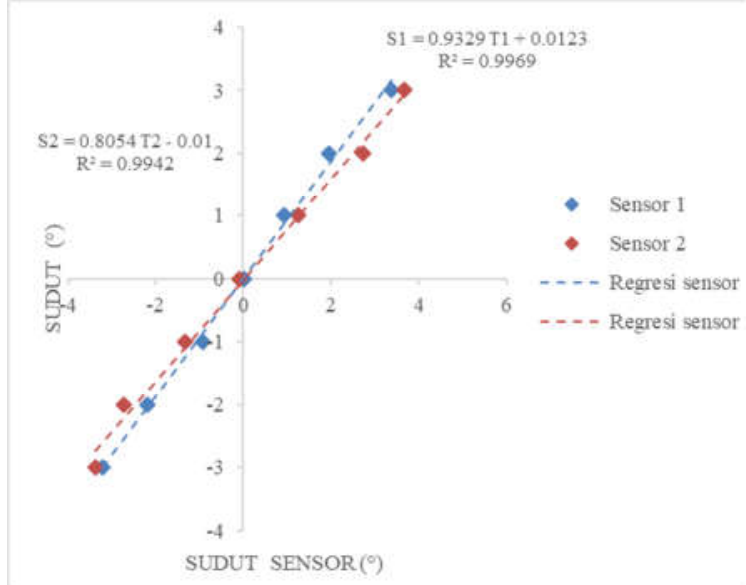

Gambar 10. Akurasi sistem sensor

Gambar 10 menunjukkan bahwa akurasi ratarata untuk sistem sensor 1 sebesar 93,29\% dan untuk sistem sensor 2 sebesar 80,54\%. Akurasi yang dimiliki oleh sensor masih terlalu kecil, sehingga perlu ditingkatkan dengan menambahkan persamaan pada fungsi kalibrasinya menggunakan persamaan garis yang didapat dari hasil uji akurasi. Pada persamaan, $\mathrm{S}$ merupakan sudut sebenarnya dan T merupakan sudut yang dibaca sensor. Fungsi kalibrasi untuk sensor 1 yaitu $\mathrm{S} 1=(93,29 \mathrm{~T} 1+$ 1,23) dan fungsi kalibrasi untuk sensor 2 yaitu $\mathrm{S} 2=(80,54 \mathrm{~T} 2-1)$. Hasil pengujian sistem sensor setelah dikalibrasi kembali seperti Gambar 11.

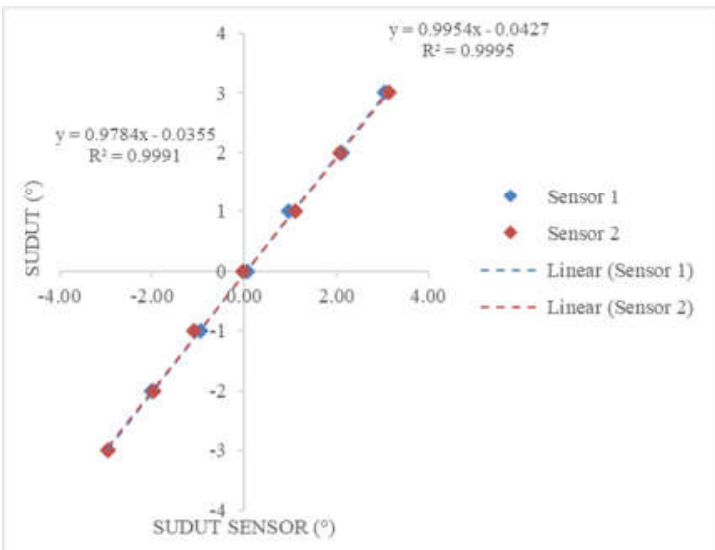

Gambar 11. Akurasi sensor setelah peningkatan

Gambar 11 menunjukkan bahwa sistem sensor memiliki akurasi yang lebih baik. Akurasi untuk sistem sensor 1 meningkat menjadi 99,5\% dan akurasi untuk sistem sensor 2 meningkat menjadi 97,8\%. Sistem sensor memiliki karakteristik yang baik dan siap untuk dijadikan sistem pendeteksi perubahan kemiringan gedung dengan sistem sensor 1 sebagai sumbu $\mathrm{x}$ sistem sensor 2 sebagai sumbu y, seperti Gambar 12. Program sistem deteksi dibuat dengan membuat program melalui Arduino IDE agar dapat membaca perubahan kemiringan gedung dan arah kemiringannya. Arduino UNO yang telah terprogram dirangkai dengan sistem sensor, buzzer, dan lcd untuk dijadikan sistem deteksi kemirngan gedung. Kemudian sistem deteksi diuji karakteristiknya.

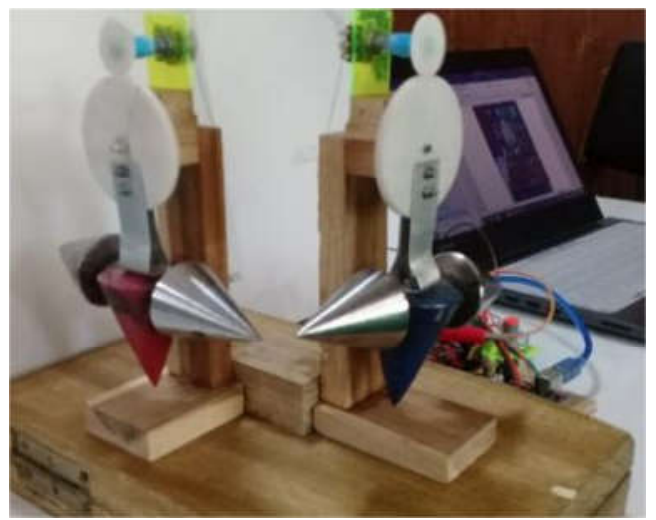

Gambar 12. Susunan sensor kemiringan arah $\mathrm{X}$ dan Y

Hasil pengujian karakteristik sistem deteksi memiliki akurasi rata-rata sebesar 89,34\%. Akurasi terendah terletak pada pembacaan arah $\mathrm{E}$ dan $\mathrm{F}$ pada sudut $1^{\circ}$ dengan akurasi sebesar $65,8 \%$. Pembacaan akurasi tertinggi terletak pada arah $\mathrm{C}$ dengan sudut $2^{\circ}$ akurasi sebesar $100 \%$. Presisi rata-rata yang dimiliki oleh sistem deteksi sebesar 91,07\%. Presisi terendah pada pembacaan arah $\mathrm{E}$ dan $\mathrm{F}$ pada sudut $1^{\circ}$ yaitu sebesar $74,52 \%$. Presisi tertinggi terletak pada pembacaan arah $\mathrm{C}$ dengan sudut $2^{\circ}$ yaitu sebesar $100 \%$. Eror rata-rata sistem deteksi sebesar $10,66 \%$ dengan eror terendah terletak pada pembacaan arah $\mathrm{C}$ pada sudut $2^{\circ}$ dengan eror $0 \%$. Eror tertinggi terletak pada pembacaan arah $\mathrm{E}$ dan $\mathrm{F}$ pada pembacaan sudut $1^{\circ}$ dengan eror sebesar $34,2 \%$. Waktu respon rata-rata sebesar 4,13 detik dengan waktu repon terendah 2 detik dan terbesar 5 detik. Pada saat perubahan kemiringan belum mencapai $1,5^{\circ}$, buzzer tidak aktif. Sedangkan pada saat perubahan kemiringan yang terdeteksi melebihi $1,5^{\circ}$ buzzer aktif. Dengan demikian sistem deteksi kemiringan gedung bertingkat memiliki karakteristik yang baik.

Waktu respon yang dimiliki oleh sensor masih terlalu lama. Hal ini terjadi karena resistor variabel yang digunakan memiliki gaya gesek yang besar sehingga sulit untuk diputar. Untuk meningkatkan waktu respon dapat 
dilakukan dengan memperbesar torsinya. Torsi dapat diperbesar dengan menambah massa beban atau lengan gayanya. Karakteristik yang dimiliki sensor untuk arah yang berlawanan seperti arah A dan arah E berbeda seharusnya sama. Perbedaan ini terjadi karena mata gear yang digunakan terlalu besar. Sehingga ketika gear besar bergerak, gear kecil belum ikut bergerak. Hal ini akan berakibat pada putaran resistor variabel sebagai sensor deteksi kemiringan. Sehingga sistem deteksi kemiringan memiliki karakteristik yang berbeda-beda untuk setiap arahnya. Arah A ditunjukkan oleh sumbu y positif, arah E pada sumbu y negatif. Arah $\mathrm{C}$ pada arah rumbu $x$ negatif dan arah $G$ pada arah sumbu $\mathrm{x}$ positif.

\section{KESIMPULAN}

Sistem deteksi kemiringan gedung bertingkat dapat dibuat menggunakan resistor variabel yang dipasang bandul sebagai sensor dengan karakteristik sebagai berikut:

\begin{tabular}{|c|c|c|c|c|c|}
\hline $\begin{array}{c}\text { Akurasi } \\
(\%)\end{array}$ & $\begin{array}{c}\text { Presisi } \\
(\%)\end{array}$ & $\begin{array}{c}\text { Eror } \\
(\%)\end{array}$ & $\begin{array}{c}\text { Waktu } \\
\text { respon (s) }\end{array}$ & \multicolumn{2}{|c|}{$\begin{array}{c}\text { Sistem } \\
\text { peringatan }\end{array}$} \\
\cline { 5 - 6 } & & & & $<1,5^{\circ}$ & $\geq 1,5^{\circ}$ \\
\hline 89,34 & 91,07 & $\begin{array}{c}10,6 \\
6\end{array}$ & 4,13 & 0 & 1 \\
\hline
\end{tabular}

\section{UCAPAN TERIMA KASIH}

Pada kesempatan ini penulis mengucapkan terimakasih kepada pihak-pihak yang sudah membantu terlaksananya penelitian ini. Penulis mengucapkan terimakasih kepada Laboratorium Elektronika Instrumentasi dan Geofisika
Jurusan Fisika FMIPA Unsoed yang sudah menyediakan fasilitas untuk penelitian.

\section{PUSTAKA}

[1] Nugraha, Y. P., Kandi, A. A. \& Prastowo, T., Pemantauan Kemiringan Gedung dan Bangunan Fisis dengan MenggunakanSensor Akselerometer ADXL335. Yogyakarta, Proseding Pertemuan Ilmiah XXVIII HFI \& DIY, 2014.

[2] Rifan, M. et al., Pemanfaatan 3 Axis Gyroscope L3G4200D untuk Pengukuran Sudut Momen Roket. Jurnal EECCIS, 6(2) (2012) 177-182.

[3] Hidayat, R., Penerapan Audio Amplifier Stereo Untuk Beban Bersama dan Berganti dengan Menggunakan Saklar Ganda sebagai Pengaturan Beban, Jurnal Teknik Elektro, 5 (2) 2013.

[4] Prayogo, W., Rivai, M. \& Budiman, F., Kontrol Lengan Robot yang Meniru Pergerakan Tangan untuk Infeksi Objek yang Mengandung Gas Berbahaya. Jurnal Teknik ITS, 7(2) (2018) ( ISSN 23373539).

[5] Halliday, D., Resnick, R. \& Walker, J., Fundamental of Physics 9th edition. 9 ed. USA, John Wiley \& Sons, Inc., 2011.

[6] Sutrisno, Elektronika Jilid 1, Bandung, ITB, 1986. 